\title{
OPTIMAL DESIGN OF POWER SYSTEM STABILIZER USING DIFFERENTIAL EVOLUTION TECHNIQUE
}

\author{
Ramadan Rajab, Tamer Fetouh, A. M. Kinawy \\ Electrical Engineering Department, Faculty of Engineering, Minoufiya University, Egypt
}

\begin{abstract}
The power system is characterized by oscillation in machine rotor angle and speed during and after the fault cases. Therefore, power system stabilizer (PSS) should be used for damping the power system oscillations. Modern optimization techniques have been applied to design (PSS) in recent years. In this paper, Differential Evolution technique (DE) isproposed as a modern technique to search for optimal controller parameters of PSS in Single Machine Infinite Bus (SMIB) system, by minimizing the deviation in the oscillatory rotor speed of the generator. Thistechnique is applied at specific operating point and at multiple operating points. Simulink \&MATLAB environmentare used to find the optimal design which is compared to other techniques such as Genetic Algorithm (GA).

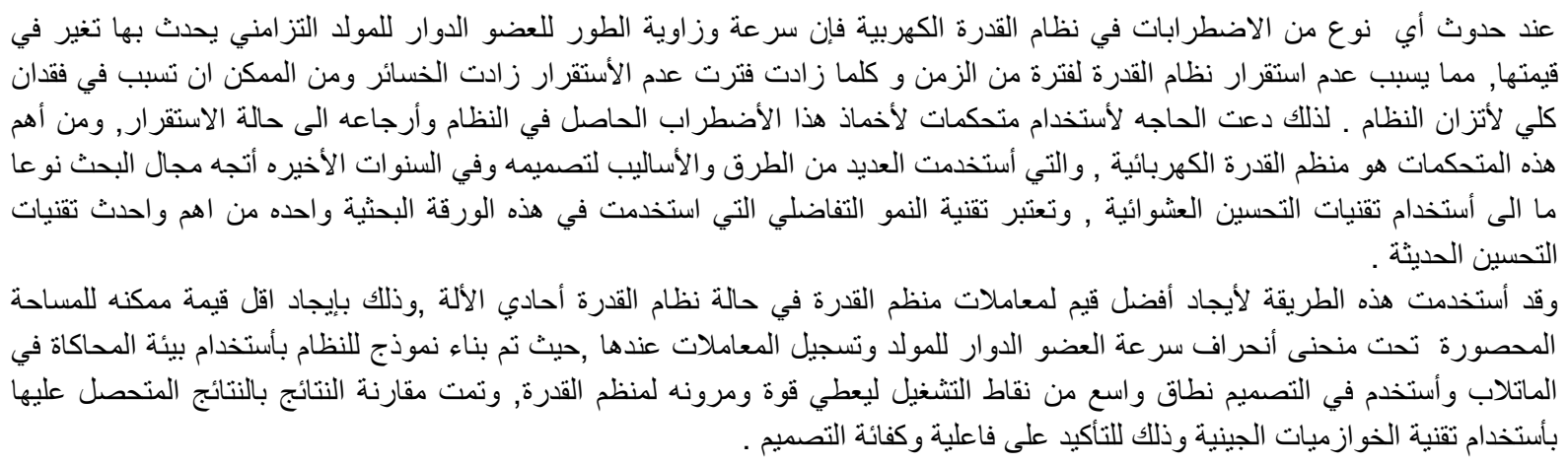

\section{Keyword:}

Powersystem stabilizer, Differential evolution technique, Single machine infinite bus, Multi operating point.

\section{Introduction}

The main reason for discriminate human and development from the middleages is the discovery of electricity, which is the basis of development and technical in this world.So, it makes sense to see that networksof electric power increased complexity evolution of mankind.This complexity requires more accurate and sophisticated techniques to maintain the stability and the reliability of the system used.One of the most important controllers is power system stabilizer (PSS). From here, increased interest in PSS over the years and development in the techniques use to obtain the preferred design to guarantee the highest levels of reliability in the event of any malfunction networks under any fault. In 1969,Demello and Concord [1]provided a basis for the design of PSS, were the first to use the theory of phase compensation in the frequency domain to make a thorough analysis of a lead-lag compensator to provide an efficient excitation system for the synchronous machine in order to utilize the control signal in the excitation system. Since the seventies of the last century, different techniques were used to design the PSS to offer the greatest possible stability, and reliability of the system.However,the techniquesof optimal and adaptivecontrol were used to design PSS [27].During the last two decades, it seems that, theuse of Artificial Intelligence Techniques such as Fuzzy 
Logic and Expert systems [8-12] is increased. Recently, the evolutionary algorithms (EAs) havetaken a great attention. Where, these algorithms are used efficiently to solve nonlinear and multiobjective optimization problems such asGenetic algorithm (GA), Tabu search algorithm (TS), simulated annealing (SA), particle swarm optimization (PSO), and Differential Evolution technique (DE) [13-21].

Recently, DE is considered as one of the efficient techniques of Evolutionaryalgorithms. It has more advantages suchas [22]:

- Fast and simple for application and modification.

- Effective global optimization capability.

- Parallel processing nature.

- Efficient algorithm without sorting or matrix multiplication.

- Self-referential mutation operation.

- Effective on integer, discrete and mixed parameter optimization.

- Ability to handle no differentiable, noisy, and/or time-dependent objective functions.

- Operates on flat surfaces.

- Ability to provide multiple solutions in a single run and effective in nonlinear constraint optimization problems with penalty functions.

Forthese reasons and other advantages, this technique is chosen in this paper. Where, DE is used to design the PSS in case of single operating point and multiple points which are compared, as well ascomparing with the GA results.

\section{Differential Evolution}

In 1995, Price and Storn proposed new evolutionary algorithm called Differential Evolution technique (DE) [23]. The DE is powerful and simple stochastic search evolutionary algorithm for global optimization. The DE consists of fourprocesseswhichcan be defined as:

- Initialization,

- Mutation,

- Crossover,

- Selection.
The initial population is chosen randomly within the range of variable bounds. Mutation and crossover are used to generate trial vectors, and after that selection determine, the vectors that will continue to next generation. In Differential Evolution there are several strategies but this paper use(DE / rand $/ 1 /$ bin) scheme which is the most successful and widely used strategy.

\subsection{Initialization}

The initial population starts with chose number and assume population=NP and Generation = Gen, generated a new value for

$$
\mathrm{X}_{\mathrm{j}}, \mathrm{j}=1,2,3 \ldots \ldots \mathrm{D}
$$

Using equation:

$$
X_{i j}(0)=X_{j}^{\min }+\operatorname{rand}(0,1)\left(X_{j}^{\max }-X_{j}^{\min }\right)
$$

Where, $I=1,2, \ldots \ldots, N P \quad, j=1,2, \ldots ., D$

$\mathrm{D}=$ number of variables, $\mathrm{NP}=$ number of members in a population, $\operatorname{rand}(0,1)$ is uniformly distributed random number between $(0,1), X_{j m a x}, X_{j m i n}$ are maximum and minimum bounds for $\mathrm{X}_{\mathrm{j}}$ after creating the initial population it evolves through mutation, crossover and selection operation .

\subsection{Mutation}

For the mutation process $\mathrm{X}_{\mathrm{r} 1, \mathrm{~g}}, \mathrm{X}_{\mathrm{r} 2 . \mathrm{g}}$ and $\mathrm{X}_{\mathrm{r} 3, \mathrm{~g}}$ are chosen randomly from current population and not coinciding the $\mathrm{Xj}$.For each target vector, a mutant vector(U) for each generation is created as follow:

$$
\mathrm{V}_{0}=\mathrm{X}_{\mathrm{r} 1, \mathrm{~g}}+\mathrm{F}\left(\mathrm{X}_{\mathrm{r} 2, \mathrm{~g}}-\mathrm{X}_{\mathrm{r} 3, \mathrm{~g}}\right)
$$

Random chosen index $r 1, r 2$ and $r 3 \in\{1,2, \ldots . N P\}, F$ $\in[0,2]$ random chosen factor.

\subsection{Crossover}

Crossover is used for increasing the diversity of population in particular.Target vector and mutated vector are merged to obtain a trial vector using the following equation:

$$
U_{i, j G}=\left\{\begin{array}{lr}
V_{i, j G} & \text { if } \operatorname{rand}(0,1) \leq C R \\
X_{i, j G} & \text { else }
\end{array}\right.
$$

Where, $\mathrm{CR} \in[0,1]$ and is selected randomly.

2.4 Selection 
The trial vector $\mathrm{U}_{\mathrm{i}, \mathrm{j}}$ is compared with the target vector $\mathrm{X}_{\mathrm{i}, \mathrm{jG}}$ and the best value of function is chosen for next generation as:

$$
\mathrm{X}_{\mathrm{iG}+1}=\left\{\begin{array}{lr}
\mathrm{U}_{\mathrm{iG}} & \text { if } \mathrm{F}\left(\mathrm{U}_{\mathrm{iG}}\right) \leq \mathrm{F}\left(\mathrm{X}_{\mathrm{iG}}\right) \\
\mathrm{X}_{\mathrm{iG}} & \text { other wise }
\end{array}\right.
$$

After that, repeat this process for all population vectors (NP), the process of mutation, crossover and selection continue until the maximum number of DE iterations is reached.

The flow chart of DEtechnique is shown in Fig. 1.

\section{System Modeling}

Single machine against infinite bus system is chosen as a test system to design the PSS using DE technique. Single line diagram for the system is shown in Fig. 2. The system parameters are given in the Appendix.

Thegenerator can be represented by 3rdorders model with three equations; two equations are differential equations for rotor electro-mechanical oscillation and one equation for internal voltage of generator.

$$
\begin{aligned}
& \dot{\delta}=\omega \mathrm{b}(\omega-1) \ldots \ldots \ldots \ldots \ldots \ldots \ldots \\
& \dot{\omega}=\frac{1}{\mathrm{M}}\left[\mathrm{T}_{\mathrm{m}}-\mathrm{T}_{\mathrm{e}-} \mathrm{D}(\omega-1)\right] \ldots \ldots \ldots \ldots \\
& \dot{\mathrm{E}_{\mathrm{q}}}=\frac{1}{\grave{\mathrm{T}}_{\mathrm{do}}}\left[\mathrm{E}_{\mathrm{fd}}-\grave{\mathrm{E}}_{\mathrm{q}}-\left(\mathrm{X}_{\mathrm{d}}-\grave{\mathrm{X}}_{\mathrm{d}}\right) \mathrm{i}_{\mathrm{d}}\right] \ldots
\end{aligned}
$$

Where,

$\delta$ is the rotor angle,

$\omega_{\mathrm{b}}$ is the reference speed,

$\omega$ is the rotor speed,

Mis the rotor inertia constant,

$\mathrm{T}_{\mathrm{m}}$ is the mechanical Torque of generator (input),

$\mathrm{T}_{\mathrm{e}} \mathrm{is}$ the electric Torque of generator (output),

Dis the rotor damping coefficient,

$\grave{\mathrm{E}}_{\mathrm{q}}$ is the generator internal voltage,

$\mathrm{T}_{\mathrm{do}}$ is the time constant of open circuit excitation,

$\mathrm{E}_{\mathrm{fd}}$ is thefield voltage,

$\mathrm{X}_{\mathrm{d}}$ is the $\mathrm{d}$-axis of steady state reactance of generator,

$\grave{X}_{\mathrm{d}}$ is the d-axis of transient reactance of generator, $i_{d}$ is the $d$-axis of stator current.
The electrical torque of generator can be represented as:

$$
\begin{gathered}
\mathrm{T}_{\mathrm{e}}=\mathrm{V}_{\mathrm{d}} \mathrm{i}_{\mathrm{d}}+\mathrm{V}_{\mathrm{q}} \mathrm{i}_{\mathrm{q}} \\
\mathrm{V}_{\mathrm{t}}=\sqrt{\mathrm{V}_{\mathrm{d}}^{2}+\mathrm{V}_{\mathrm{q}}^{2}} \ldots
\end{gathered}
$$

$$
V_{d}
$$

$$
=I_{q} X_{q}
$$

$$
\begin{aligned}
& \boldsymbol{V}_{\boldsymbol{q}} \\
& =\grave{E}_{q}-\boldsymbol{X}_{d} \boldsymbol{i}_{d}
\end{aligned}
$$

Where,

$\mathbf{V}_{\mathbf{d}}, \mathbf{V}_{\mathbf{q}}$ are the d-q axis of terminal voltage. $\mathrm{i}_{\mathrm{q}}$ is the q-axis of stator current.

$\mathrm{X}_{\mathrm{q}}$ is the $\mathrm{q}$-axis reactance of the generator. 


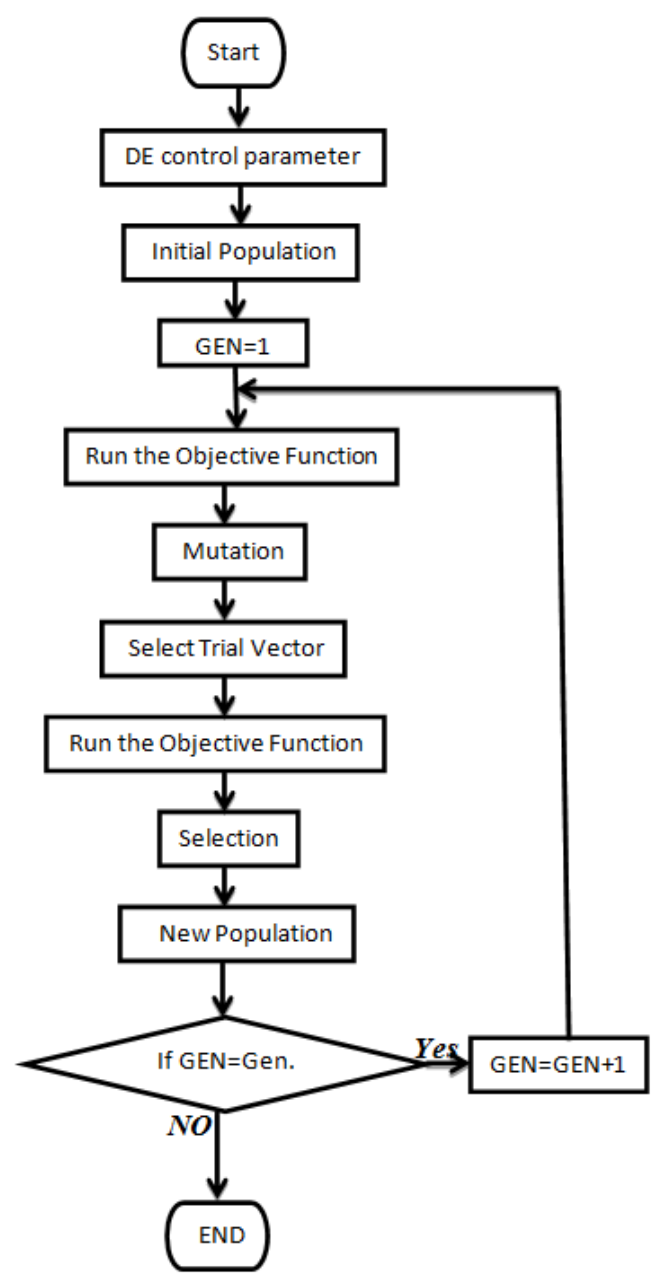

Fig. Iflow chart of Differential Evolution technique

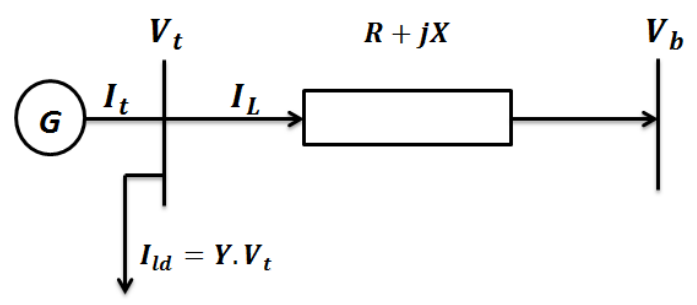

Fig. 2Single machine infinite bus

Excitation system with PSS is shown in Fig.3

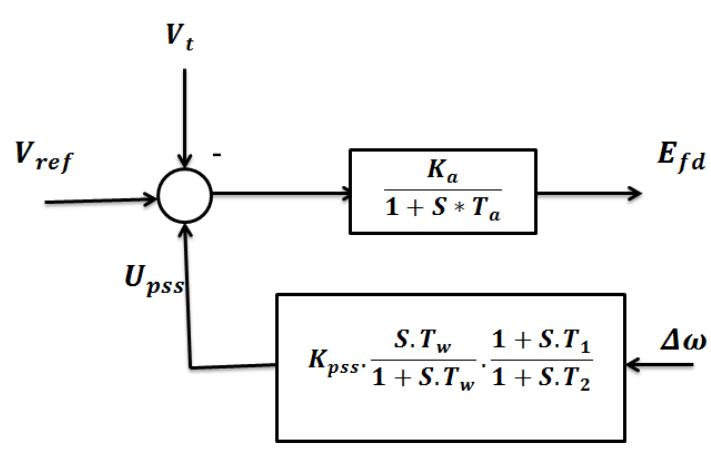

Fig.3 Excitation system with PSS

The main idea of the exciter is regulating the output voltage of generator by controlling the field current; the field voltage can be represented by the following equation:

$$
\begin{gathered}
\dot{E}_{f d}=\frac{1}{T_{a}}\left[K_{a}\left(V_{r e f}-V_{t}+U_{p s s}\right)\right. \\
\left.-E_{f d}\right] \ldots(8)
\end{gathered}
$$

The stabilizing signal, which is the output of the PSS is given by:

$$
\begin{gathered}
U_{p s s}=\Delta \omega \cdot \frac{S T_{\omega}}{1+S T_{\omega}} \cdot \frac{1+S T_{1}}{1+S T_{2}} \\
\cdot K_{p s s} \ldots(9)
\end{gathered}
$$

Where,

$\mathrm{K}_{\mathrm{pss}}$ is the stabilizer gain.

$\mathrm{T}_{\omega}$ is the wash out time constant.

$\left(\mathrm{T}_{1}\right.$ and $\left.\mathrm{T}_{2}\right)$ are the time constants of the onestagelead/lag phase compensator.

4. Problem Formulation

The parameters of PSS $\left(\mathrm{K}_{\mathrm{pss}}, \mathrm{T}_{\omega}, \mathrm{T}_{1}\right.$ and $\left.\mathrm{T}_{2}\right)$ need to be optimized in order to improve the system performance. The nonlinear model of the system introduced by Equations (1)-(9) is used in order to estimate the fitness function for the DE technique.

\subsection{Objective function}

The main objective of PSS is to damp the oscillations in rotor angle and speed.Therefore, single objective functions $\mathrm{j}_{1}$ andj $\mathrm{j}_{2}$ can be used in the 
optimization process. On the other hand, multiobjective function $\mathrm{j}_{3}$ can be used by merging $\mathrm{j}_{1}$ and $\mathrm{j}_{2}$ with specific weighting factors $\mathrm{a}, \mathrm{b}$.

The objective functions are defined as follows:

$$
\begin{aligned}
& \mathrm{j}_{1}=\int_{\mathrm{T}_{\mathrm{f}}}^{\mathrm{T}_{\mathrm{s}}}|\omega-1| \cdot \mathrm{dt} \\
& \mathrm{j}_{2}=\int_{\mathrm{T}_{\mathrm{f}}}^{\mathrm{T}_{\mathrm{s}}}\left|\delta-\delta_{0}\right| \cdot d \mathrm{t} \\
& \mathrm{j}_{3}=\mathrm{a} * \mathrm{j}_{1}+\mathrm{b} * \mathrm{j}_{2} \cdots
\end{aligned}
$$

Where,

$\mathrm{T}_{\mathrm{S}}$ is the simulation time,

$\mathrm{T}_{\mathrm{f}}$ is the fault instant,

The weighting factors are selected as: $(a=10$ and $b=$ 0.2 ).

The optimization problem can be formulated as :

Minimize $\mathrm{j}_{1}, \mathrm{j}_{2}$, or $\mathrm{j}_{3}$

Subject to

$$
\begin{array}{r}
\mathrm{K}_{\mathrm{pss}-\min } \leq \mathrm{K}_{\mathrm{pss}} \leq \mathrm{K}_{\mathrm{pss}-\max } \\
\mathrm{T}_{1-\min } \leq \mathrm{T}_{1} \leq \mathrm{T}_{1-\max } \cdots \cdots \cdots \cdots \\
\mathrm{T}_{2-\min } \leq \mathrm{T}_{2} \leq \mathrm{T}_{2-\max } \cdots \cdots \cdots \\
\mathrm{T}_{\omega-\min } \leq \mathrm{T}_{\omega} \leq \mathrm{T}_{\omega-\max } \cdots \cdots \cdots \cdots
\end{array}
$$

Typical ranges of the optimized parameters are [0.1100] forK $_{\mathrm{pss}},[0.1-1]$ for $\mathrm{T}_{1},[0.05-2]$ for $\mathrm{T}_{2}$ and [0.5-5] for $\mathrm{T}_{\omega}$.

\section{Results and discussions}

The operating point of the system is not constant all the time. So, the effect of changing the operating point should be studied. The optimization process is applied at specific operating point (single point) as well as (multiple points) design. The system response should be justified at any operating point when the PSS parameters are designed at singlepoint or multiple-points.

Table1 shows the PSS parameters which are optimized at single-point.
Table1 Single point designed parameters of PSS

\begin{tabular}{|l|l|l|c|c|l|}
\hline $\begin{array}{l}\text { Operating } \\
\text { point }\end{array}$ & \multicolumn{5}{|c|}{ PSS parameters } \\
\hline $\boldsymbol{P}$ & $Q$ & \multicolumn{1}{|c|}{$K_{\text {pss }}$} & \multicolumn{1}{|c|}{$\boldsymbol{T}_{1}$} & $T_{2}$ & \multicolumn{1}{|c|}{$\boldsymbol{T}_{\boldsymbol{\omega}}$} \\
\hline 0.1 & 0.075 & 100 & 0.599 & 0.05 & 5 \\
\hline 0.2 & 0.15 & 100 & 0.5224 & 0.05 & 5 \\
\hline 0.3 & 0.225 & 83.8576 & 0.3263 & 0.05 & 2.11 \\
\hline 0.4 & 0.3 & 84.7785 & 0.2689 & 0.05 & 5 \\
\hline 0.5 & 0.375 & 79.2025 & 0.2571 & 0.05 & 5 \\
\hline 0.6 & 0.45 & 73.2865 & 0.25 & 0.05 & 5 \\
\hline 0.7 & 0.525 & 68.718 & 0.2479 & 0.05 & 5 \\
\hline 0.8 & 0.6 & 66.8051 & 0.251 & 0.05 & 5 \\
\hline 1 & 0.015 & 36.712 & 0.3171 & 0.05 & 3.77 \\
\hline
\end{tabular}

However,Table 2 shows the PSS parameters obtained with multiple-points design. Where, wide ranges of operating points are used.

Table2Multiple-points designed parameters of PSS

\begin{tabular}{|c|c|c|c|}
\hline$K_{p s s}$ & $T_{1}$ & $T_{2}$ & $T_{\omega}$ \\
\hline $\mathbf{8 0 . 2 9 3 4}$ & $\mathbf{0 . 2 6}$ & $\mathbf{0 . 0 5}$ & 5 \\
\hline
\end{tabular}

All of the above results are obtained using DE with the following parameters:

\section{$G=200, N P=40, F=0.9, C R=0.5$}

Figures 4, 5 show a comparison between the system (rotor speed and angle) when the parameters are optimized by DE and GA. TheseFigures show the improvement of the system response using the DE compared with GA.The comparison is carried out at the operating point $\left(\mathrm{P}=1, \mathrm{Q}=0 .{ }^{1 \bullet}\right)$.

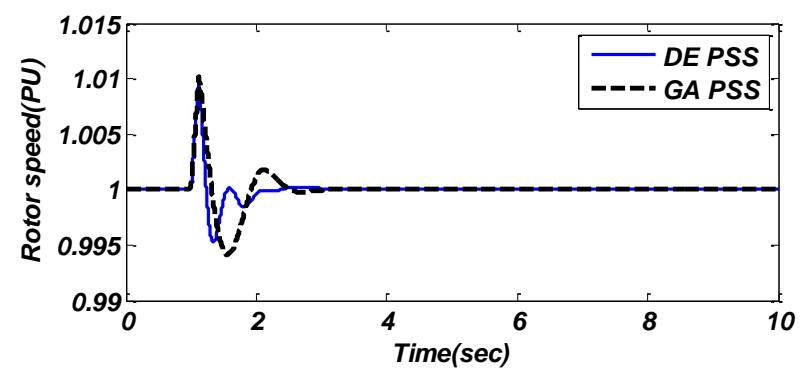

Fig. 4 Rotor speed 


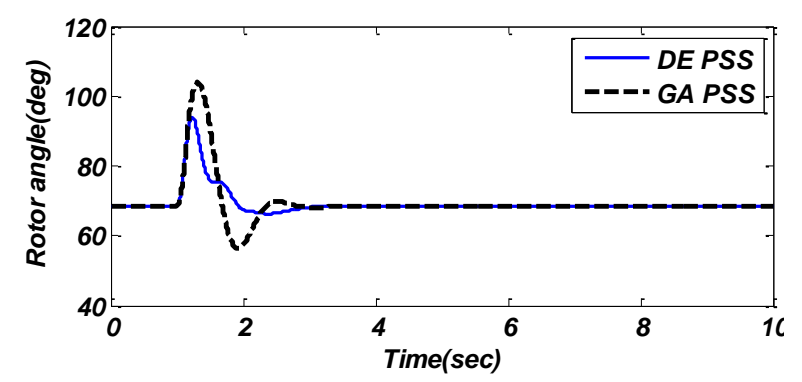

Fig. 5 Rotorangle

Figures 6 and 7 show the rotor angle and rotor speed responses at the operating point $(\mathrm{P}=0.1, \mathrm{Q}=0.075)$. The PSS parameters are designed using thesinglepointconditionas well as the multiplepointscondition.

Figures 8 and 9 show the rotor angle and rotor speed responses at the operating point $(\mathrm{P}=0.2, \mathrm{Q}=0.15)$. The PSS parameters are designed using the singlepointconditionas well as the multiplepointscondition.

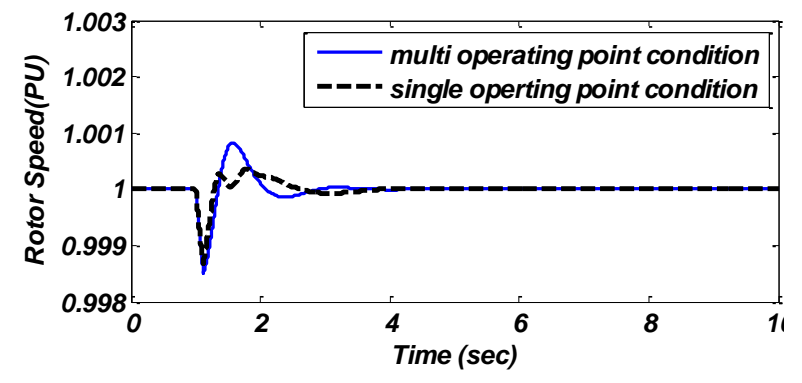

Fig. 6 Rotor speed for single and multi operating conditions

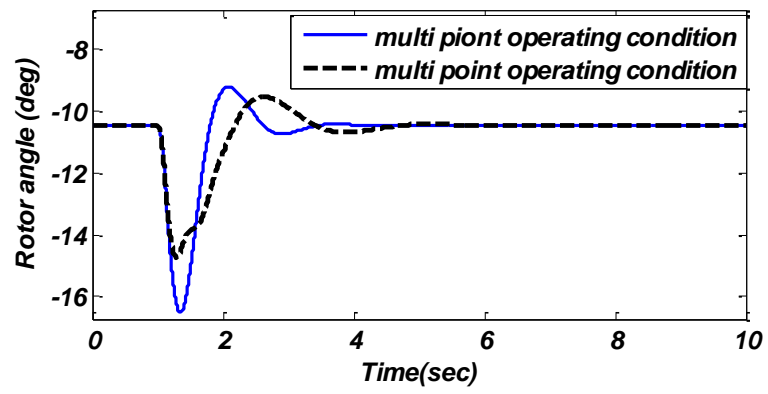

Fig.7 Rotor angle for single and multi operating conditions

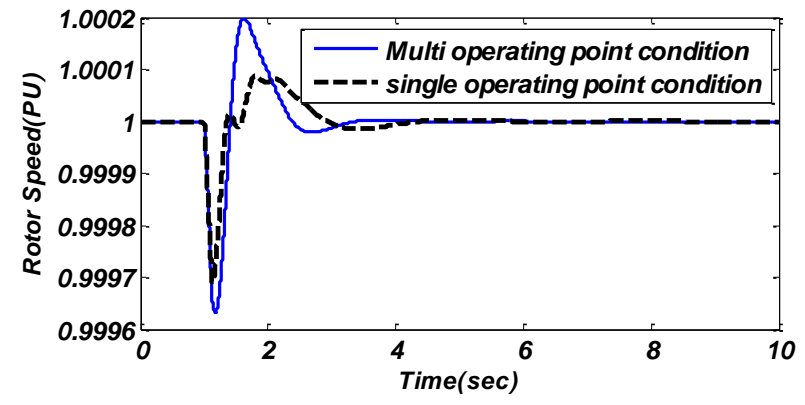

Fig.8Rotor speed for single and multi operating conditions

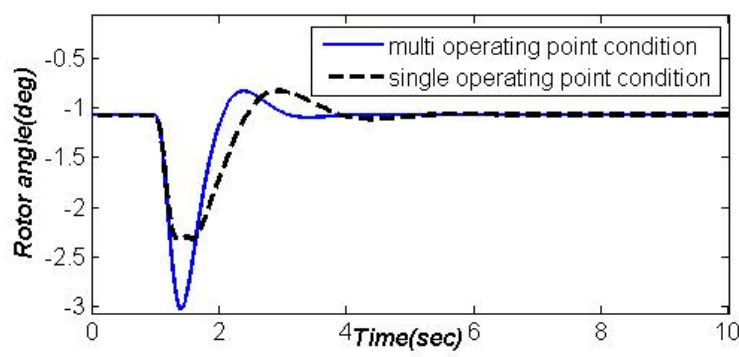

Fig.9Rotor angle for single and multi operating conditions

The system response to short circuit near to the infinite bus is checked and compared for two cases, single point design and multiple point design. Figures 6-9 show a comparison between the system responses for the two cases. It is logic to have better response of the system when using the single-point design. Since, the PSS parameters are designed at the single-point. But, how the system response will be? if the PSS parameters are designed at specific point $(\mathrm{p}=1.0, \mathrm{Q}=0.015 \mathrm{p} . \mathrm{u})$ and the system operate at another point $(\mathrm{P}=0.1, \mathrm{Q}=0.075 \mathrm{p} . \mathrm{u})$. To get the answer of this question see Figs. 10 and 11, which show the rotor speed and angle response to 3-phase short circuit near the infinitebus.

It is clear from these figures that, the system response using multiple-points designis better than that of single-point design. 


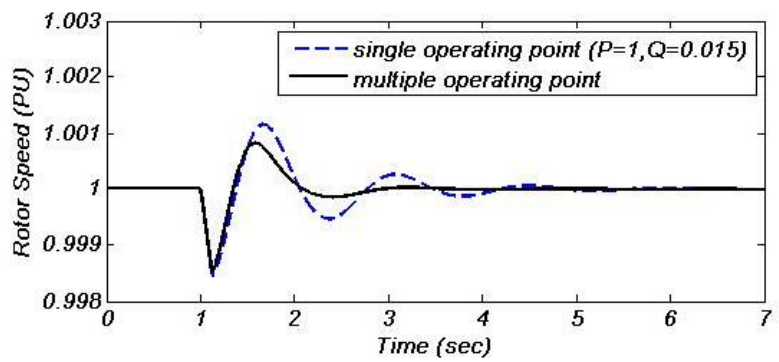

Fig. 10 Acomparison between single and multiple design response for rotor speed

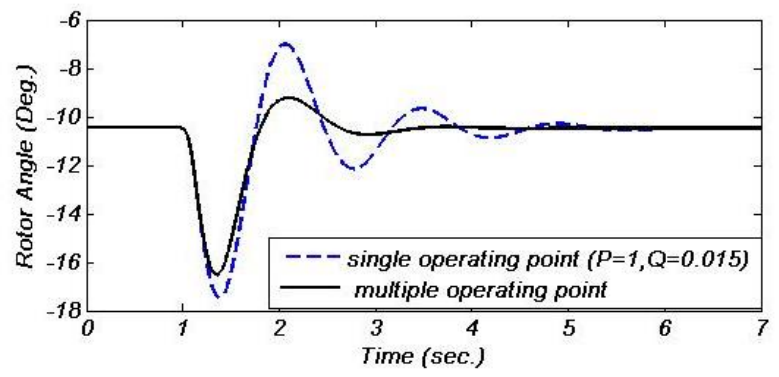

Fig. 11 A comparison between single and multiple design response for rotor angle

\section{Conclusions}

An improvement in the optimization process has been obtained using the proposed DE technique compared with the GA. The PSS parameters have been designed successfully by the proposed DE. Also, the single-point designed parameters and multiple-points designed parameters have been tested and compared, considering the change in the system loading conditions, however, the multiplepoints design get more better response.

\section{REFERENCES}

[1] F. P. Demello, and C. Concordia, "Concepts of synchronous machine stability as affected by excitation control", IEEE Transaction on Power System Apparatus, PAS 88, No.(4), pp. 189 - 202, 1969.

[2] A. J. A. S. Costa, F. D. Freitas and H. E. Peña. "Power system stabilizer design via structurally constrained optimal control", Electric Power System Research. Vol. 33, pp. 33-40. 1995.

[3] T. L. Huang, T. Y. Hwang, and W. T. Yang, "Two level optimal output feedback stabilizer design“, IEEE Transactions on Power Systems, Vol. 6, No. 3, pp. 1042-1048, August 1991.
[4] P. H. Huang, and Y. Y. Hsu, " An output feedback controller for a synchronous generator", IEEE Transactions on Aerospace and Electronic Systems, Vol. 26, No. 2, pp. 337-344, March 1990.

[5] A.S. Ibrahim, B.W. Hogg, M.M. Sharaf, "Selftuning controllers for turbo generator excitation and governing systems", IEE Proc. Vol. 136 (5), pp.238 -251, (1989).

[6] S. Zhang, F.L. Luo, "An improved simple adaptive control applied to power system stabilizer IEEE Transactions on power electronics, Vol.2 \&, No.2, pp.369-375, Feb. 2009.

[7] C.J. Wu, Y.Y. Hsu, "Design of self-tuning PID power system stabilizer for multimachine power systems", IEEE Trans. PWRS 3,pp 1059 - 1064, (1988).

[8] Wenxin Liu, Ganesh K. Venayagamoorthy, Donald C. Wunsch. "Adaptive neural network based power system stabilizer design", Proceedings of the International Joint Conference on Neural Networks, pp 29702975, 2003.

[9] M. L. Kothari, Ravi Segal, Bhushan K. Ghodki." Adaptive conventional power system stabilizer based on artificial neural network", International Conference on Power Electronics,Drives and Energy Systems for IndustrialGrowth, Vol.2, pp 1072-1077, jan 1996.

[10] D. K. Sambariya, R. Gupta, A. K. Sharma, "Fuzzy applications to single machine power system stabilizers", Journal of theoretical and applied information technology, Vol.5, No. 3, pp. 317-324, 2009.

[11] Hariri, A. and Malik, O.P., "A Fuzzy Logic Based Power System Stabilizer with Learning Ability". IEEE Transactions on Energy Conversion, Vol. 11, No. 6, pp 721 - 727, Dec. 1996.

[12] Jenica Ileana Corcau and EleonorStoenescu "Fuzzy logic controlled as power system stabilizer" International Journal of Circuits, System and Signal Processing, Vol.1, Issue.3, pp.266-273, 2007.

[13] Sumathi N, Selvan MP, Kumaresan N. A "hybrid genetic algorithm based power system stabilizer", International conference on 
intelligent and advanced systems, ICIAS, pp. 876-881, 2007.

[14] Abdel-Magid YL, Abido MA. "Optimal multiobjective design of robust power system stabilizers using genetic algorithms", IEEE Transactions on Power System, Vol. 18: pp 1125-1132, 2003.

[15] Mishra S, Tripathy M, Nanda J. "Multimachine power system stabilizer design by rule based bacteria foraging", Electric Power Systems Research;Vol.77:pp 1595-1607, 2007.

[16] Abido M. A. "Robust design of multi-machine power system stabilizers using simulated annealing”, IEEE Trans Energy Conver; 15: pp 297-304, 2000.

[17] Abido MA, Abdel-Magid YL. "Robust design of multi-machine power system stabilizers using tabu search algorithm", IEE Proc-Gener Trans Distribut; 147: pp 387-94, 2000.

[18] Sumanbabu B, Mishra S, Panigrahi BK, Venayagamoorthy GK. "Robust tuning of modern power system stabilizers using bacterial foraging algorithm", In: 2007 IEEE congress on evolutionary computation (CEC 2007); pp. 2317-24, 2007.

[19] Mostafa HE, El-Sharkawy MA, Emary AA, Yassin K." Design and allocation of power system stabilizers using the particle swarm optimization technique for an interconnected power system", International journal of Electrical power and Energy systems; 34, pp 57-65, 2011.

[20] Eslami M, Shareef H, Mohamed A, Khajehzadeh M. "Damping of power system oscillations using genetic algorithm and particle swarm optimization", International Review of Electrical Engineering, Vol. 5, pp. 2745-2753, 2010.

[21] Shayeghi H, Shayanfar H. A., Safari A, Aghmasheh R. A.,"Robust PSSs design using PSO in a multi-machine environment", Energy Convers Manage; 51: pp 696-702, 2010.

[22] K. Y. Lee and M. A. El-Sharkawi, "Modern heuristic optimization techniques: Theory and applications to power systems", Wiley-IEEE Press, 2008.
[23] Price K, Storn R, Lampinen J. "Differential evolution - a practical approach to global optimization”, Berlin: Springer; 2005.

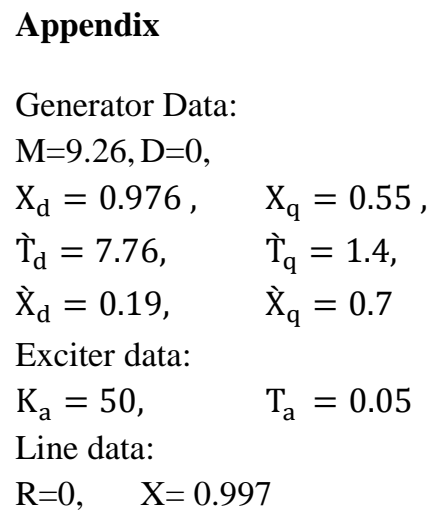

For GA the PSS parameters at $\mathrm{P}=1, \mathrm{Q}=0.015$

\begin{tabular}{|c|c|c|c|}
\hline$K_{p s S}$ & $T_{2}$ & $T_{1}$ & $T_{\omega}$ \\
\hline 24.8396 & 0.1581 & 0.0647 & 0.726 \\
\hline
\end{tabular}

